\title{
Genochondromatosis type 1
}

INSERM

\section{Source}

INSERM. (1999). Orphanet: an online rare disease and orphan drug data base.

Genochondromatosis type 1. ORPHA:85197

Genochondromatosis is characterized by chondromatosis, typically involving the clavicles, upper end of the humerus, and lower end of the femur. Lesions are bilateral and symmetrical. It has been described four patients from the same family and is transmitted as an autosomal dominant trait. Another disorder, genochondromatosis II, shows strong similarities to genochondromatosis but is characterized by the involvement of the short tubular bones and by normal clavicles. It has been described in one unrelated family. Genochondromatosis II may also be inherited as an autosomal dominant trait. Genochondromatosis has a benign clinical course. 